\title{
The impact of emergency aid work on personal relationships: a psychodynamic study
}

\author{
Mark Snelling ${ }^{1,2}$ (D)
}

\begin{abstract}
Humanitarian organisations and researchers have paid increasing attention in recent years to the psychological wellbeing of aid workers. This attention, however, has tended to focus more on the practicalities of stress management and resilience than on the deeper levels of their relational lives. This qualitative research study explored the conscious and unconscious impact of emergency aid work on the personal relationships of those who deliver it. Six experienced staff members of an international non-governmental organisation (INGO) were invited to reflect freely on their relationships in unstructured interviews. Using psychoanalytic theory, the data were analysed for both surface and hidden content. Every participant identified the significant external split that aid work created between home life and the field and described conscious strategies to manage this challenge. Their narratives, however, also indicated deeper inner dilemmas along with more unconscious strategies for protecting themselves against the anxiety generated by those dilemmas. Although deployed in response to the relational demands of the work, these strategies also appeared to form part of patterns of relating developed prior to entry into the sector. The study concluded that structured spaces where humanitarians can reflect on these issues would be beneficial both to personal resilience and to organisational effectiveness.
\end{abstract}

Keywords: Humanitarian aid worker, Relationships, Trauma, Psychodynamic, Psychosocial support

\section{Introduction and rationale}

There is an old joke in the humanitarian aid sector that those who work in it are either "misfits, mercenaries or missionaries" (Silverman 2005). Making light of the complex mix of motives that draw people into the field may alleviate some of the stress of a very challenging environment. The joke, however, also points to a recognition that the choice of career can involve a great deal more psychological and emotional complexity than a straightforward desire to help the world's poor and dispossessed. Few jobs are as "all-encompassing" (Fechter 2012b) as international humanitarian work, requiring people to live far from their homes and families, often lodged in close proximity to their colleagues while exposed to traumatic events, traumatised individuals, or both. At the same time, the short-term

\footnotetext{
Correspondence: mark@marksnelling.co.uk

${ }^{1}$ Department of Social and Political Science, University of Chester, Parkgate Road, Chester CH1 4BJ, UK

${ }^{2}$ Mark Snelling Therapy, Parkshot House, 5 Kew Road, Richmond, Surrey Tw9 2PR, UK
}

nature of most assignments, especially for those who specialise in emergency response, results in a transient lifestyle that poses particular risks to the maintenance of consistent support structures (McKay 2007). Without these structures, both research (Cardozo et al. 2012; Ozbay et al. 2007) and anecdotal evidence in the field demonstrate that it can be very difficult to maintain resilient functioning.

The motivation for this study has arisen from my own experiences of humanitarian field work in Africa, Asia and the Middle East, first as a delegate of the British Red Cross Society (BRCS) from 2000 to 2007, and subsequently as a psychosocial consultant. In both capacities, I have observed that the struggle to maintain viable relational support structures is commonplace, consuming a lot of time and emotional energy. As a clinician, I have also been repeatedly struck by how often my humanitarian clients cite relational difficulties, not exposure to trauma, as a primary source of distress in the field. Even work with those specifically presenting for trauma treatment seems often to link to problematic relationships. Yet while there is a 
substantial body of research on stress management, resilience and trauma care for aid workers (see "Literature review" below), little specific academic attention has been directed towards their relational worlds.

Further research, along with exploration of these questions in personal therapy, have also prompted me to question whether these difficulties are purely a consequence of working in aid or are, at times, a manifestation of personal relational templates that pre-date people's entry into the sector. And while other helping professions, such as counselling, social work and nursing consider reflection on the personal aspects of practitioners' lives to be a critical component of ethical practice (Hawkins and Shohet 2012), formal processes that would facilitate this are strangely missing in humanitarian aid (Fechter 2012b).

In seeking to address these questions, this study is grounded in psychodynamic ${ }^{1}$ theory, the body of thinking pioneered by Freud that suggests people protect themselves from anxiety by pushing unacceptable thoughts, wishes and feelings out of conscious awareness (Freud $1915 / 1968 b)$. Advances in contemporary psychoanalysis have also placed increasing emphasis on the ways in which these unconscious anxieties can exert a powerful and potentially problematic influence over people's current relationships (Lemma et al. 2011; Mitchell 2000; Stack Sullivan 1968). Finally, psychodynamic workplace research indicates that a failure to address these individual anxieties can lead to significantly wider dysfunction in organisational dynamics and performance, especially in the helping professions (Obholzer and Zagier Roberts 1994).

While the sector routinely debates how it needs to adapt to external political, economic and sociological factors (Inter-Agency Regional Analysts Network [IARAN] 2017) in the face of widespread criticism of its perceived failings (de Waal 1997; Easterley 2007; Moyo 2010; Riddell 2008), the present study seeks to focus on what might be learned by attending to the internal relational worlds of humanitarian workers. It could be argued that recent scandals involving sexual misconduct among expatriate aid workers (Dodds 2017; O'Neill 2018) have added urgency to the need for humanitarian workers and their organisations to understand and monitor interpersonal needs and how they get met. Further research is needed on the specific links between individual anxiety and organisational dynamics in the humanitarian sector, but the present study will focus on the conscious and unconscious impact of humanitarian work on the relationships of those who undertake it. At the same time, it will also consider the potentially pre-existing patterns of relating that they may be bringing into the profession in the first place.

The central aims of the present study were as follows:

- To explore the literature on humanitarian aid workers with particular attention to personal relationships in order to identify potentially underexamined areas and, as a result, provide a focussed framework for this study.

- To identify and outline the key relational challenges described by study participants, with a particular focus on the ways in which these challenges register in their inner emotional and psychological worlds.

- To use psychoanalysis and attachment theory as a framework for conducting an in-depth exploration of the unconscious psychological strategies deployed by study participants to manage and cope with these challenges.

- To draw out practical measures that humanitarian workers and organisations could implement to help them cope with the relational demands of the work.

It is important to state at the outset that this study was based on interviews with expatriate aid workers and as such does not reflect the relational experience of nationally hired staff, who work in their home countries, or non-Western expatriates. There is no doubt that the mental health of national staff demands more attention than it receives (Ager et al. 2012; Porter and Emmens 2009). While consideration of the impact on local workers is beyond the scope of the present study, it is hoped that the psychodynamic approach taken here to examine expatriate experience could open future avenues of research to include all staff groups. It is also hoped that the present study will initiate a more active debate over whether an increased understanding and care for the internal psychological and emotional worlds of aid workers, expatriate and local, could benefit the overall effectiveness of the global humanitarian project.

\section{Literature review}

The evolution of today's international humanitarian system can be characterised by a multitude of social, economic and political factors, but certain key developments stand out; the massive post-World War II proliferation of agencies, the broadening global reach of humanitarian activity and the emergence of so-called complex emergencies in the 1990s (Davey et al. 2013). As the work of humanitarian aid became ever more complex, demanding and dangerous, researchers began to turn their attention not just to the sector itself, but to the people who worked in it (Slim 1995).

Most academic studies on aid workers (see below), along with a range of guidelines and manuals issued over the years (e.g., Antares Foundation 2012; Macnair 1995; People in Aid 2003), have focussed on the operational challenges of stress management and the resilience strategies available in response to highly demanding environments. These will be considered first before turning to the small but expanding literature over the past 10 years 
on the more subjective thoughts and feelings of aid workers (including personal motives). It will then be considered how the wider psychodynamic literature on attachment might help deepen an understanding of the relational patterns of those who work in the humanitarian sector.

\section{The birth of stress management}

Following the end of the Cold War in 1991, an apparently more peaceful international environment quickly gave way to a surge in particularly destructive conflicts in places such as Liberia, Sudan and the former Yugoslavia, characterised by substantial loss of civilian life, massive displacement of populations and decimation of social and economic structures (Duffield 1994). While the humanitarian sector rushed to adapt logistically to the large-scale, multi-pronged responses now required (Davey et al. 2013), voices within the sector began to consider the possible impact on the people delivering the assistance. In a seminal conference paper (1995), Hugo Slim set out what he felt were the new skills for aid workers that these "radically different" (p. 2) emergencies would require, including negotiation and conflict analysis. Although Slim only made brief mention of the emotional needs of aid workers, his paper was representative of a new interest in the lives of humanitarians themselves, alongside those of the beneficiaries of aid.

A year later, the Overseas Development Institute (ODI) published a report (Macnair 1995) commissioned by a group of agencies looking at levels of organisational support for expatriate aid workers. As the title "Room for Improvement" suggested, the report uncovered weaknesses across a range of human resources management practices in the sector, leading to both poor performance by staff and a reduction in the quality of programmes (Macnair 1995). The report fed into a much larger project, culminating in the publication 2 years later of the "People In Aid Code of Best Practice in the Management and Support of Aid Personnel" (People in Aid 2003), aimed at equipping managers and human resources advisors. Like much of the writing at the time, the report focused mainly on practical occupational health challenges but did not consider the emotional or relational challenges. In 1998, the stress management unit of the International Committee of the Red Cross (ICRC) published its findings (de Haan 1998) on the impact of psychological debriefing on returning workers and a year later, the British Medical Journal (BMJ) featured an article (McCall and Salama 1999) on the selection, training and support needs of aid workers, noting that their mental health and the impact of their work was still relatively unstudied. At around the same time, the ICRC (de Haan 2001) along with the United Nations (UNHCR 2001) and other large agencies (Fawcett 2003) began releasing more comprehensive stress management manuals for aid workers. In 2004, the publication of the "Guidelines for Good Practice: Managing Stress in Humanitarian Workers" (Antares Foundation 2012), a collaboration between the Antares Foundation in the Netherlands and the Centers for Disease Control (CDC) in the USA, represented a new level of conceptual sophistication in humanitarian staff care frameworks. As occasional articles and chapters (Danieli 1996) on the welfare of aid workers became whole books devoted entirely to this area (Ehrenreich 1999), it seemed that the physical and psychological health of humanitarians had become established as a discrete domain of research and study. An initial focus on practical stress management, however, was soon to evolve.

\section{Towards resilience}

Outside the humanitarian sector, the 1990s onwards saw a shift in the psychology literature from a concentration on risk factors, namely the causes and symptoms of psychological distress, towards a greater strengths-based focus on how people maintain emotional and physical resilience in the face of adversity (Cyrulnik 2009; Reich et al. 2012; Seligman 1990). An early study on resilience in the humanitarian arena (Berk 1998) examined the way in which both child victims and aid workers in Bosnia drew on very similar strategies, such as cognitive restructuring, to support resilient coping. Later studies (Ehrenreich and Elliott 2004; Eriksson et al. 2001) identified the need for organisational inputs such as training and on-going support to promote and bolster the individual resilience strategies of aid workers. Researchers also began including the role of spirituality (Blanchetiere 2006) and religious faith (Eriksson et al. 2009) in supporting resilient functioning. The first major longitudinal study of the mental health of humanitarian workers (Cardozo et al. 2012) confirmed that workers with access to robust support structures, such as reliable friendship groups, coherent teams and accessible psychological services, were less vulnerable to depressive illness and burnout. In the light of chronic exposure to acute stress, however, researchers confirmed that aid workers experienced higher levels of trauma-related mental illness (Connorton et al. 2012) than other professional groups and were particularly vulnerable to burnout (Pigni 2016). As such, efforts continue to identify effective self-care and organisational support strategies (Dunkley 2018; Quevillon et al. 2016).

\section{Subjective experience of aid workers}

Writing on the more personal, subjective experience of aid workers first emerged mainly in memoirs of life in the field, offering colourful, first-person accounts of the dilemmas and disillusionments of the work (Cain et al. 2005; Orbinski 2008; Vaux 2001). These were later joined by a multitude of blogs ranging across a broad 
spectrum of both content and quality. Popular examples include Aid Leap (https://aidleap.org), Stuff Expat Aid Workers Like (https://stuffexpataidworkerslike.com) and 50 Shades of Aid (https://www.facebook.com/groups/ 1594464844163690).

An early academic study (Bjerneld et al. 2006) of the psychological dynamics of aid workers focused on motivation, identifying a range of drivers ranging from an altruistic desire to help others to a wish to feel personally needed and fulfilled. A later study (Tassell and Flett 2007) considered humanitarian activity in the light of Self-Determination Theory (Deci and Vansteenkiste 2004), a broad framework for examining human motivation. Drawing on the concept of "harmonious and obsessive passion" (Vallerand et al. 2003), the study (Tassell and Flett 2007) explored two potential motivational forces in aid workers, one that represented a freely chosen desire to work in harmony with personal values and self-perception and another driven by a more obsessive need to acquire a sense of social acceptance or self-esteem. The study (Tassell and Flett 2007) made an important contribution to the understanding of humanitarian resilience in its finding that individuals driven by obsessive passion were likely to continue in the work even when it became detrimental to their wellbeing, thus significantly increasing the risk of burnout.

Although neither of the above-mentioned studies drew on psychodynamic theory, they signalled a curiosity about the unconscious forces that may be at work in aid workers' lives. This has been accompanied in more recent research by more nuanced examinations of deeper emotional reactions to exposure to conflict, including self-doubt, shame and isolation (McCormack and Joseph 2013), along with more focussed attention on the role of interpersonal networks in supporting the resilience of humanitarian workers (Thomas 2016). It is also only in recent years that studies have begun to consider not just the impact of the work on field staff, but pre-existing factors and traits, such as childhood trauma (Eriksson et al. 2013), a need for self-reliance and a reluctance to seek help from others (Skeoch et al. 2017).

Although research on humanitarian workers themselves seems to be expanding and deepening, anthropologists have identified the striking lack of attention given to the personal aspects of aid workers' lives by training institutions and organisations, especially given the importance assigned to personal considerations in other helping professions such as counselling, nursing and social work (Fechter 2012b). Although studies seem to be implicitly considering the more unconscious aspects of aid workers' minds, psychodynamic approaches to this area are again striking in their absence. Berk's previously cited study (Berk 1998) of aid workers in Bosnia is the only article on humanitarians in the entire PEP-Web database of psychoanalytic texts. A search of the PsycINFO database using the terms "humanitarian" and "psychodynamic" yielded only one article (Karray et al. 2017) looking at the dynamics of online support to field staff. While there is a well-established psychodynamic literature on refugees and the victims of humanitarian crises (Alayarian 2011; Papadopoulos 2002; Volkan 2017), there is very little published research into the unconscious dynamics that might be at play among aid workers.

The motivation to undertake psychodynamic research into the impact of aid work on personal relationship arises, therefore, from what appears to be the relative neglect of a central area of their experience, both in the research literature and in the stress management and resilience information distributed by organisations. Anecdotal evidence gathered from personal experience in the field, first-person written accounts of field life and substantial clinical experience all indicate high levels of relational distress among those who do this work, especially when it comes to maintaining an intimate partner relationship. Yet much of the published advice given to humanitarians on life in the field remains strangely silent on this issue.

\section{Methodology}

The research was conducted using the Free Association Narrative Method (Hollway and Jefferson 2013), a psychodynamically oriented methodology aimed at capturing both conscious and unconscious aspects of experience. Freud believed that the need to suppress undesirable emotions resulted in the creation of a part of the self that faces out to the world-the ego-and an inner less conscious part that is subject to powerful instincts and drives-the id Freud (1917/1957). This psychic structure is then maintained by a series of defences that protect the self against anxiety Freud (1968a, 1968b/1915/b), including repression (Freud 1968b/1915/b), a process as noted previously whereby unacceptable psychic content is ejected from consciousness. In splitting (Freud 1940), the mind separates what is seen to be threatening and destabilising from what appears to be nourishing and supportive in order to protect what is good from being overwhelmed by the bad. And in projection (Klein 1946), emotional parts of the self that are deemed to be unacceptable are then pushed into the outside world and attributed to other people.

Klein (1946) based her theory on close observation of the ways in which young infants evacuate feelings of rage and helplessness into the mother as a way of managing otherwise unbearably vulnerable internal states (Berzoff and Kita 2010). The psychoanalyst Wilfred Bion (1959) extended Klein's thinking by considering how anxious adults, also, will non-verbally expel overwhelming feelings into others as both a way of stabilising themselves, but also as a primitive form of 
communication, transmitting important information to the listener that can be picked up and received (Hinshelwood 1991). Bion (1962) observed that if the mother is able to take in and make sense of those anxieties before reflecting them back to the infant in a more manageable form, a process he described as containment, the baby is then able to return to a state of calm. For adults, the same principle can be applied to the way that counsellors, psychotherapists and supervisors help adults by actively listening to their potentially overwhelming experiences before reflecting on them in a way that makes them more bearable (Casement 2014). The idea of containment has also been used by organisational theorists (Obholzer and Zagier Roberts 1994) to explore the ways in which groups and organisations can manage and process the anxieties of those who work within them, as well as the difficulties that arise in terms of team dynamics when those unconscious anxieties are not identified and dealt with.

In order to tune into and pick up this kind of non-verbal communication, the interviews themselves were conducted using a core technique drawn from psychoanalytic psychotherapy for accessing unconscious material described by Freud as free association (Breuer \& Freud, 1895/1955). It was explained to participants that the interview would be unstructured, and they were invited to speak in an uncensored way about whatever came to mind in relation to the research question. Little guidance was offered regarding any expected content, and little intervention was offered by the researcher during the interview. Once collected, the interviews were then analysed not just for manifest content, but also for inconsistencies, contradictions, slips of the tongue and body language. Psychoanalytic theory contends that all of these factors can be read as indicators of unconscious content (Hollway and Jefferson 2013). Several participants, for instance, lost fluency in otherwise verbally coherent narratives when they tried to speak about the challenge of maintaining intimacy, potentially signalling unconscious blockages in engaging with this aspect of their lives. The technique, then, offers insight into hidden dynamics and motivations that would never be visible in either quantitative research or more face-value types of qualitative work (Frosh and Saville Young 2008).

\section{Participants}

The six participants in the research were all professional aid workers, drawn from the emergency roster of a large International Non-Governmental Organisation (INGO). Aged between their early thirties and early sixties, four participants were women and two were men. Two were currently deployed in the field, two were back in their home countries on leave between assignments, one had taken time out from field work, and one was in a country other than her home country that she had chosen to make her base between missions. Three of the participants spoke English as a first language, two were bilingual and one spoke English as a second language.

In terms of socio-cultural context, all the participants were situated within the Western expatriate culture of the global humanitarian sector. While two participants came from families with at least one non-Western parent, the conversations with all participants were framed by concerns consistent with a more individualised Western worldview, such as the importance of self-expression (Kim and Sherman 2007). Care was taken not to make generalised assumptions about the participants, who described a variety of diverse priorities, personal values and experiences, but it is important to state that they did so from within a relatively homogeneous socio-cultural frame. It should also be noted that the psychoanalytic methodology used in the present study is also grounded in a Western clinical tradition that has been slow to pay full attention to the impact of social, ethnic and cultural influences on people's inner worlds (Tummala-Narra 2015). Having said that, there is an expanding literature examining the cross-cultural applications of psychoanalysis (Alayarian 2011) and attachment theory (Agishtein and Brumbaugh 2013; Erdman and Ng 2010; Mesman et al. 2016). In the final analysis, however, the present study is authored by a western researcher focussing on the inner experience of a small group of western or westernised aid workers. As noted previously, the aim is to initiate further discussion and research and caution is needed in generalising the findings. In particular, further cross-culturally oriented research would be needed before applying its findings to non-Western humanitarian staff, both expatriate and national.

A brief summary of each participant is provided below (Table 1).

\section{Reflexive statement}

Alongside the participants' narratives, the methodology takes a position that the researcher's own experiences, thoughts and feelings can also provide context and insight into the participant's material in a way that yields accurate and valuable information (Holmes 2013). In this case, my own knowledge and personal experience of the sector, combined with insights from personal therapy and clinical experience were included as anecdotal evidence in support of the study's findings.

In terms of autobiographical context, I spent many years in the field, first as a journalist and then as an expatriate humanitarian aid worker. Having suffered from major depression for many years, I made the decision to return to my home country, the UK, and undertake long-term psychoanalytic psychotherapy. Having benefited significantly from the process, I then re-trained as a 
Table 1 Summary of participants

\begin{tabular}{lll}
\hline Name $^{\text {a }}$ & Biographical details & Psychosocial formulation \\
\hline Julian & $\begin{array}{l}\text { Senior manager with } 20 \text { years of field experience, married with } \\
\text { a stable home base. }\end{array}$ & $\begin{array}{l}\text { Presented as confident and securely attached but acknowledged } \\
\text { internal conflicts and high personal cost of the work. }\end{array}$ \\
Thomas & $\begin{array}{l}\text { Senior manager with } 25 \text { years of field experience, in a long-term } \\
\text { "open" relationship }\end{array}$ & $\begin{array}{l}\text { Presented as calm and measured. Although he described himself as } \\
\text { approachable, he evidenced traits of an avoidant attachment style }\end{array}$ \\
Jane $\quad \begin{array}{l}\text { Had taken a mid-career break from the field in order to reflect on } \\
\text { her life and build a more stable home base. Described a close circle } \\
\text { of female friends but no partner. }\end{array}$ & $\begin{array}{l}\text { Presented as active and engaged but somewhat anxious. Had used } \\
\text { counselling to try and work through a perceived struggle to integrate } \\
\text { different areas of her life. }\end{array}$ \\
Anna & $\begin{array}{l}\text { Was currently on deployment, away from a secure home base and } \\
\text { long-term partner. }\end{array}$ & $\begin{array}{l}\text { Presented as calm and level-headed but concerned by a sense that } \\
\text { field work is incompatible with longer-term family life. Evidenced } \\
\text { avoidant attachment traits. }\end{array}$ \\
Emma & $\begin{array}{l}\text { Experienced senior manager, currently between deployments. } \\
\text { Married with children having established a home base in an } \\
\text { adopted country. }\end{array}$ & $\begin{array}{l}\text { Presented as confident and assertive but indicated high levels of } \\
\text { frustration with the difficulties of adapting to life outside the field. } \\
\text { Indicated anger at having been assigned a coping role in family of } \\
\text { origin. } \\
\text { Sara }\end{array}$ \\
$\begin{array}{ll}\text { Experience practitioner based at HQ with frequent travel to the } \\
\text { field. Described global friendship circle but no partner. }\end{array}$ & $\begin{array}{l}\text { Presented as a motivated and principled individual, with strong } \\
\text { beliefs in personal autonomy. Also evidenced avoidant attachment } \\
\text { traits and had sought counselling to explore continuing lack of } \\
\text { intimate partner relationship. }\end{array}$ \\
\hline
\end{tabular}

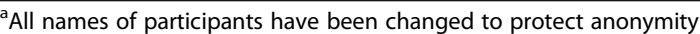

bSee "Attachment styles" section for definitions and discussion

psychotherapist myself. Many years of personal reflection and therapy yielded an understanding that while my decision to enter the humanitarian sector had indeed been motivated by an altruistic wish to make a difference in the world, it had simultaneously been driven by a powerful but unconscious wish to manage and master anxieties stemming from attachment disruptions much earlier in childhood. Working as a humanitarian had, in part, enabled me to disown unbearable feelings of vulnerability and locate them externally in the so-called beneficiaries of the aid that he was helping to deliver. In relational terms, it also manufactured a sense of interpersonal proximity while avoiding the perils of genuine intimacy.

In undertaking this study, then, I identified a clear risk that I might only look for validation of my own experience. The alternative, however, was to fully declare my own experience and use it as a tool and a guide, a stance known as researcher reflexivity (Etherington 2004). Etherington (2004, p. 31) defines reflexivity as "the capacity of the researcher to acknowledge how their own experience and contexts (which might be fluid and changing) inform the process and outcomes of inquiry". Far from blinding me, this stance closes what she calls the "illusory gap between researcher and researched" (Etherington 2004, p. 32 ), creating "a relationship with participants ... of consultancy and collaboration" (Etherington 2004, p. 32), which in turn generates an interactive energy in research interviews that can yield accurate and valuable information. In simple terms, I undertook this study backed by substantial experience of the sector, experience which I used "for the purpose of extending sociological understanding" (Wall 2008, p. 38) of my subject matter.
In addition to the contextual knowledge, the data were also analysed through the filter of my own emotional reactions to the narrative, understood in psychoanalytic terms as "counter-transference" (Heimann 1950), or the receipt of unconscious projections from the participant. This further elaborated and deepened an understanding of the participant's "total situation" (Joseph 1985), a psychoanalytic concept denoting a full understanding the way an individual's patterns of relating are transferred from the past to the present. These diverse strands were then gathered into an overall psychodynamic formulation regarding the impact of aid work on the relational lives of the participants incorporating both conscious and unconscious aspects of their narrative.

\section{Limitations}

While the psychoanalytic method has the potential to illuminate the unconscious dynamics that exist behind participants' presenting positions (Frosh and Emerson 2005), it could be argued that the findings of a psychoanalytically oriented interview are "inevitably and intrinsically the product of the particular researcher-interviewee dyad" (Holmes 2013). Given that the counter-transference reactions of any researcher will be determined by the interaction between the projections of the participant and specific elements of his or her own inner world, it is quite possible that another researcher could experience those projections differently and therefore draw different conclusions. Efforts have been made in the present study, therefore, to adhere to quality indicators of transparency and reflexivity to ensure that readers are able to see clearly where interpretations and conclusions have been drawn from these interpersonal dynamics. 
It could also be argued that aid workers who are more likely to have experienced relational challenges as a result of their jobs will have self-selected to participate in this study. Again, however, their narratives were analysed in the context of the author's own experience of the sector, both as a worker himself and as a clinician supporting humanitarian staff. So while caution is required in generalising the findings of the study, it can be argued that the multiple strands of contextual data that frame the participants' accounts generate an "enrichment of interpretive understanding" (Frosh and Emerson 2005, p 308), providing in turn a solid basis for tentative but reliable conclusions.

\section{Findings}

The following section will present the findings of the study, detailing the particular relational demands and challenges reported by participants when invited to reflect on the impact of their work on their relationships. Five major themes emerged across the narratives of all six participants: (1) A radical split in their lives on both an external level, between home and the field, and on an internal level, between different parts of their personality; (2) a conviction that the split was irreconcilable; (3) the long-standing search for belonging; (4) repetitively unproductive relational patterns; (5) a sense of not knowing.

\section{A radical split}

From the interviews, one could conclude that life for expatriate humanitarian workers is a mixed blessing. On the one hand, they are privileged cosmopolitan professionals whose "transnational lives" (Fechter 2007) afford them a "world right to circulate unhindered" (Croucher 2012). In stark contrast to "disadvantaged travellers" (Redfield 2012b) such as migrants, refugees and asylum seekers, the people who undertake to provide assistance to these populations stand to accrue a range of personal and financial benefits from their work, including frequent travel, an interesting lifestyle, the opportunity to save money (Fechter 2012a) or the cultivation of personal meaning (Thomas 2016). They are, of course, also potentially sustained by altruistic motives, even if those are inevitably mixed with self-interest (Tassell and Flett 2011; Vaux 2001). At the same time, however, humanitarian workers are separated from their family units and home friendship groups (Fechter 2012b), while often living in unusual proximity with co-workers in the field (i.e. confined to a compound under curfew). So, while the separation between work and home life is almost non-existent in the field ("You can hardly escape your colleagues," according to Julian), the participants in this present study spoke unanimously about the challenge of coping with the much wider gulf between their professional and personal lives.
Participants cited a range of concrete, external challenges generated by this split, including finding and maintaining an intimate relationship, maintaining a circle of friends, establishing and maintaining a physical home base and managing the amount of time spent in the field versus time needed at home. In terms of finding a partner relationship, the two male participants had found apparently stable but different solutions. Julian had married a local woman in the African country where he was first assigned. Thomas, the oldest of the participants, had found the answer in agreeing to an "open" arrangement with his partner back home. Both men expressed satisfaction in the stability that these relationships provided them amidst the frequent travel of their working lives.

The picture for the two women in long-term partnerships seemed more complicated. Jane barely mentioned her husband, either in positive or negative terms, raising a question about the strength of his presence in her life. It was hard to tell if a long-term relationship did in fact help her. Anna reported a stable and supportive relationship with a partner at home who did not work in the sector, but disclosed having a relationship with someone else in the field as a coping strategy in the aftermath of a traumatic incident a few months previously. Unlike Thomas, who felt that extra-marital relationships were entirely acceptable, Anna appeared more conflicted by behaviour that she viewed as "360 degree of who I usually am".

The two single women interviewed approached the issue of partners somewhat differently. Emma spoke favourably about her support group of single female humanitarian friends, but worried that the group had set up a "kind of self-fulfilling cycle" of singleness. At the same time, she seemed to assiduously avoid talking about men, indicating a continuing difficulty in fully encountering the issue and associated feelings. I wondered also if it felt challenging for her to name this difficulty to a male researcher. Whether or not that was the case, the avoidance seemed to reflect the overall difficulty in the sector of naming discussing widely prevalent, yet deeply personal concerns.

Sara appeared to have less difficulty in referencing the search for "the love of my life" but was unsure if moving back to the UK would help. She said friends were advising her "to put down roots, in order to be able to meet someone and sustain it over the long-term", but said she felt "you can meet someone anywhere". At the same time, she noted the "very shallow" nature of relationships in the field, losing coherence in a way that seemed to imply, but not quite name, the sexual promiscuity that many field workers report as standing in for more sustained relationships.

All participants stressed the importance of maintaining friendships, but there was variation between them as to whether those friends were inside or outside the humanitarian sector. Both Sara and Anna talked about the 
importance of "personal" friendship circles back at home, noting the intensity but transience of friendships in the field. Jane and Emma on the other hand felt very wedded to friends within the sector, looking to them for validation and support. For the men, Thomas referred to a circle of friends but seemed much less intentional about maintaining those relationships and Julian spoke somewhat poignantly about a wish to spend time with close friends that "of course is not going to happen."

All of the participants felt it was important to maintain a physical home base, either in their country of origin or in an adopted homeland, which ranged from owning a house to maintaining a room in a friend's apartment. They all also spoke about the need to balance time in the field with time at home and most were intentional about ensuring that several months a year were spent away from the field. Emma, for instance, had decided to spend an extended period of time in the UK in response to a growing concern over what she saw as the impoverishment of her personal life resulting from so much time in the field: "I think it has been very important for mental health (to return to the UK), I kind of was craving that sense of normality."

While every participant reported proactive measures to manage the external split between home bases and field locations. Most participants (5/6) described a far more complex struggle to manage a perceived internal split between different parts of their personality.

Julian: "I have become a split personality. One person who lives and moves in this world, and one person who lives and moves in that world."

Anna said that she found it easy to switch between field and her "very, very different life" back at home, but immediately pointed to a split so complete that "I even look different" in each place, suggesting quite a radical separation. Almost every participant wondered which part of them was "real". Emma indicated a similar concern, describing the feeling of a "work mask" coming back on in the field. It was striking how tiring it felt at times to listen to these narratives, which triggered memories from my own career of just how emotionally and physically draining it is to live with this kind of fragmentation, a reality supported by Horney (1972) in her classic psychoanalytic study of the emotional toll of inner conflicts.

\section{Double-bind}

However participants framed this split, the majority $(5 / 6)$ expressed the view that it confronted them with a sense of contradictory and apparently irreconcilable demands in their relational life. On the one hand, they expressed a sense of vocation, engagement and satisfaction in their work as humanitarians, including powerful feelings of camaraderie and shared understanding with colleagues. On the other, they also expressed deep-seated needs for continuity, belonging and connection in their home settings. For many though, these two equally valid realities could not be reconciled with each other, leaving them in what the pioneer of systemic family therapy, Bateson et al. (1963), described as a double bind. Bateson and his colleagues initially coined the term in relation to the onset of schizophrenia, describing the collapse of any ability to establish a sense of order in the world (Gibney 2006). It has subsequently been extended as a framework for thinking about impossible dilemmas and the distress they cause, "a choice between two states which are equally valued and so equally insufficient that a self-perpetuating oscillation by any active choice between them" Wilden and Wilson (as cited by Redfield 2012b, 1976). Given the impossibility of the double-bind, participants in the present study expressed feelings across the board of stuckness, not knowing, and even despair at ever being able to find a solution.

Jane, for example, described a deep conflict between her love of the work and her wish to be with her children at home, but also expressed the fear that this left her feeling as if she had some kind of "personality flaw". This reflects Gibney's assertion (Gibney 2006) that the experience of double-bind is literally "crazy-making" (p. 48). Having decided to spend some time back in the UK, Emma joked that she could be driven to becoming "that crazy angry person who may just want to go back to the field", masking what seemed like a genuine concern with humour.

\section{Search for belonging}

If participants expressed frustration at how stuck they felt in this double-bind, they also almost universally (5/6) spoke about the way in which the humanitarian sector had initially seemed to promise a deep sense of belonging and connection that it had ultimately failed to deliver.

Both Sara and Emma referred to their colleagues in familial terms. (In the author's experience, both as a field worker and a clinician who supports field workers, humanitarians often speak of their teams as surrogate family units.) For Sara, the shared experience of working for her team had enabled her to build "quite strong relationships", "basically you kind of have a ready-made family and support network when you are away, because they are in a similar situation to you". Disappointingly, however, relationships forged in the field could ultimately "feel very shallow". Emma, also talked about finding a "family":

"I found my true tribe, these are my people!"

As time had gone on, however, she said she had found herself feeling increasingly depleted, rather than 
supported and nourished. "By year four and five, you are like, 'Now I am really fed up by this'."

The idea that humans engage in an on-going search for relationships that feel reliable and enduring lies at the heart of attachment theory (Holmes 2014). Bowlby (1988), its pioneering thinker, believed that if children grow up an environment where caregivers are responsive, reliable and consistent in their care, they will develop what he called a secure base, namely a sense of inner stability and confidence that emotional and physical needs can be met. In adult life, humans continue to engage in secure base behaviour (Holmes 2001) at times of stress in order to calm and soothe themselves. Whether through positive and beneficial actions such as talking to friends, resting and reading or negative and self-defeating strategies such as substance misuse, disordered eating and self-harm, people will seek to maintain a sense of security, whatever the consequences (Holmes 2001). Viewing the narratives in the present study through this lens, then, raises the idea that participants initially felt that the people and places accessed through humanitarian aid offered a reliable secure base. Their widely expressed (4/6) view, however, was that the promised sense of security turned out to be less reliable than initially thought.

\section{Repeating patterns}

Alongside the disappointment at not being able to sustain a sense of belonging, a feeling that was expressed by half the participants was that this was a problem that was somehow self-perpetuating. Although participants were able on the face of it to identify the dilemmas, incompatible demands and unfulfilled hopes, they also spoke as if they were stuck in a repeating pattern from which they could not extricate themselves.

On three occasions, Emma used the term "sucked into" to describe her sense of being pulled back into work environments, indicating powerful forces acting seemingly against her will. In terms of how this works in practice, she described an "echo chamber" created by her group of female colleagues that reinforced the compulsion to return to the field. Sara suggested that the humanitarian world actually attracts "people who do not belong". The sense of inner displacement that they are already carrying then "gets replicated" by the perpetual movement. Her perspective points to the possibility that the repetitive sense of dislocation reported by participants may not, in fact, have been caused by working in the sector, but be driven by personal factors that brought them into it.

Freud (1914/1957) was one of the first to identify the way in which experiences in childhood that are experienced as overwhelming or traumatic in some way are pushed into the unconscious mind. Instead of remembering the unbearable memory, then, the individual goes through life simply repeating something of that experience instead Freud (1920/1957). While on one level this can be seen as an attempt to master the original trauma Freud (1957a), it can also be a mechanism that simply condemns the individual to repeat and reinforce it (Van der Kolk 1989). In the context of the present study, the theory of repetition compulsion suggests that rather than becoming passively stuck in a chronic struggle to connect, there may be something in the participants' lives that drives them to actively and repeatedly seek that experience out. This idea will be discussed at greater length below.

\section{Not knowing}

Amidst the many challenges cited by participants, a recurring theme (5/6) was quite simply the absence of answers, a sense of not knowing what to do. At different points in her interview, Emma described almost every group of people in her life as either not knowing anything or not wanting to know anything meaningful. Her family, she said, "have not made an attempt to try and understand more". Friends back at home seemed only interested in trivia. A therapist that she tried to see had appeared overwhelmed by the content and context of what she was bringing: "She could not professionally handle the conversation". Things were not much better in the field. During the Ebola crisis, she said she felt "no one had a clue" and during another deployment in central Africa, "you really did not know what was going on". In connection to the relational dilemmas that she faced, Anna was similarly despairing:

"No one really has a solution, and you just kind of hear a lot of sad stories about people just jumping from relationship to relationship, or from friendship to friendship, so like no one really has a solution for it."

In most cases, it was striking how categorical participants were about not knowing. There was a concrete quality to not having answers, as if these were challenges that one could not be curious about in a way that might yield possible solutions; as Allen put it, a problem of "too little imagination" (Allen 2013) when it comes to possible solutions. Anna, for instance, said that the only possible answer in the future would be to leave the sector. Julian too, was certain that if humanitarian workers began a relationship with each other, one if not both would have to leave for the relationship to survive. It could be argued that this apparent certainty represented a mental stance knows as psychic equivalence, in which inner thoughts and feelings are equated with external reality (Allen 2013).

In this instance, the fact that answers do not seem available is taken to mean that answers do not exist, 
indicative of a collapse in so-called reflective functioning, or the "capacity to reflect on internal mental states such as feelings, wishes, goals, and attitudes, with regard to both the self and others" (Fonagy et al. 2016). Difficulties with this kind of reflecting - also known as mentalizing-are known to be associated with vulnerability to depression (Lemma et al. 2011), but can also lead to a variety of psychological problems (Bateman and Fonagy 2012). It can then be argued that the sense of not knowing represents not just a distracting annoyance for participants, but a significant risk factor to levels of on-going resilience.

On a broader level, the view expressed by participants that-to borrow from Hollywood screenwriter William Goldman (2012)_-"no one knows anything", seemed to be a source of continuing anxiety. In psychodynamic terms, this could be framed as an almost complete absence of containment (Bion 1962). Participants were clearly expressing anxiety, but they were also clearly describing a sense of there being no one around (individually or institutionally) who could help them make sense of it. As Anna said: "No one really has a solution". In fact, at least half the participants seemed to be saying that a reason they had volunteered to take part in the research was a hope that the conversation itself might in some way serve to shed some light on these dilemmas.

\section{Discussion}

The present study found a high level of agreement among participants concerning a range of challenges that humanitarian workers face in their relational lives, which chimed with my own personal experience on multiple levels. As noted previously, the more practical, external and conscious aspects of managing the demands of life in the field have been well covered elsewhere (Dunkley 2018; McKay 2007; Pigni 2016). The aim of the following discussion, however, is to explore the findings through the lens of two overlapping bodies of psychodynamic theory, psychoanalysis and attachment theory, with a view to drawing out the potentially unconscious defences that humanitarians deploy to cope with these challenges.

\section{Splitting and projection}

The idea of a split has emerged repeatedly in different ways in the present study, both as an externally imposed division of life between the field and home and more internal sense of a splitting of the personality between who they feel themselves to in work settings and at home. While both perspectives view the split as a demand to be met, field work, psychoanalytic theory also suggests that it might be an internally generated strategy for defending and protecting themselves against the psychological threats that they face.
In terms of the present study, splitting and projective defences were identifiable in two different forms. Participants seemed either to present an idealised version of themselves by splitting off and assigning undesirable qualities to others (either colleagues or people back at home), or they created a split internally between a supposedly strong capable part of themselves and more vulnerable and potentially needy part that needs to be suppressed. It was also interesting for me as the interviewer to note where my sense that I was the recipient of unconscious projections, otherwise known as counter-transference (Hinshelwood 1991), appeared to communicate strong messages from the internal worlds of the participants.

Jane's narrative, for instance, seemed to indicate quite profound splitting. She spoke in highly idealising terms about life in the field: "I can make a big difference, it's fast-moving, it interests me". She also spoke in highly denigrating terms about the people she met back at home: "You just want to eat your own eyeballs, they are just so boring". Although the tone of her narrative at times like this was half-joking, the violence of the language seemed to indicate a level of barely concealed anger. At one point, she alluded to a wish that she could just sometimes just say, "For God's sake, I am tired" and have that heard and understood. But a more tyrannical part quickly took over: "But then you kind of do not want to sound like a winge-er, so you do not".

Throughout the interview, I had a sense of being urgently asked to reassure and validate her struggle. "I mean you must have this feeling as well", she said at one point. I did indeed recognise the feeling and recalled with some discomfort the complex and contradictory mix of both victimised and persecutory feelings from life in the field. Significantly for Jane, she had recently attended a workshop where space and time had been given to relational dilemmas, which she said had been a revolutionary experience. So, while acknowledging the "superwoman" persona, she seemed to have been finally given an opportunity to express feelings of confusion and fatigue that were then validated by others. In terms of the research question, it was striking that Jane had apparently carried personal and relational challenges of such magnitude for so long without being able to openly discuss them. Her huge relief was also noteworthy in that such an apparently simple solution could feel like such an effective response to apparently very complex issues.

\section{Addiction to emergency}

As noted in the findings, participants described the uncomfortable challenge of feeling stuck in self-perpetuating relational and behavioural patterns. The majority (4/6), however, also acknowledged an addictive quality to both 
the experience of deploying to humanitarian contexts as well as to the kinds of interactions that they found there. For example, Thomas described getting "hooked to that kind of emergency relationship" in the early years of his career, something he felt he needed less of as he had got older. On a wider level, he used the same word talking about getting "hooked when there's a huge emergency and everyone wants to be part of it".

Considering briefly the anthropology of humanitarianism, Redfield (2012a) argued the urgent action demand by states of emergency offer the "comforting justification" that inequalities in the world are temporary and can be redressed. In psychological terms, this idea could be re-framed as viewing the immediacy of emergency as a soothing distraction from the reality of underlying and much more intractable unmet needs. In psychodynamic terms, intolerable inner dramas can be split off and ejected into the outside world, where they can be played out as "transitional theatre" (McDougall 1982) in the paradoxically less threatening external environment.

According to Emma, "there's a lot to be said around the adrenalin buzz of also being at the heart of the biggest thing going on at the time." Relationally, she described it as "exciting (that) you are back with the same people, we are a good team, we are going to have a great time". But straight away she framed this almost in terms of an addict's relapse: "You kind of managed to get away from it, and then you get sucked straight back into it again." Anna too seemed to find something soothing in emergency contexts: "My personality is very much kind of more comfortable doing the riskier deployments ... Generally, I am good in emergencies." Interestingly, of all the participants, only Anna referenced exposure to external trauma in the field as a stress factor, and even then, only as the trigger for a relational difficulty.

So, far from being a source of difficulty for emergency aid workers, it appeared from the present study that the kinds of traumatised environments that they work in can actually represent some kind of coping resource. Of the six participants, four referred to field work as a "bubble", somehow removed from "normal" life. While this could be viewed as potentially problematic, the soothing qualities mentioned above also indicate that the bubble is protective. This fits with Steiner's observations (Steiner 1993) that some people remain addictively wedded to avoidant defences that may be uncomfortable on the one hand, but are maintained as a refuge, or psychic retreat, from harsh reality.

Alongside a psychodynamic reading of this repetition, the addictive nature of the work can also be understood in terms of physiological responses. As previously noted, several participants mentioned the (albeit temporary) benefits of the adrenalin released in emergency contexts, fuelling feelings of excitement and competence. If the adrenalin provides energy to give people a boost, Van der Kolk (1989) has demonstrated that repeated exposure to inescapable stress releases endogenous opioids in the human body that provide soothing relief from anxiety. Naparstek (as cited by Thomas 2016, 2005) has also argued that individuals can become addicted to their own biochemical responses to trauma, setting up a self-perpetuating cycle of behavioural re-enactment. Taken together then, it can be concluded that emergency contexts have the capacity to help people manage and regulate their moods, either upwards or downwards, in ways that can, like any other chemical addiction, become compulsive.

\section{Attachment styles}

Although beyond the scope of the present study, further detailed research is needed considering humanitarian relationships through the prism of attachment theory, the framework for understanding the psychodynamics of interpersonal relationships pioneered by John Bowlby and Mary Ainsworth (Holmes 2014). They and their successors sought to understand how early experiences in life shape the way people experience stress and develop relational strategies in order to cope (Holmes 2014). These strategies become entrenched as attachment styles Ainsworth et al. (1978) or particular patterns of relating that people carry into adulthood. A number of different attachment style classifications have been developed, but they can be summarised as secure, anxious, avoidant or disorganised (Bifulco and Thomas 2013).

All the participants referenced experiences in early life that they felt has shaped their present approach to relationships. Julian, Jane and Sara all referenced early experiences of feeling like an "outsider", albeit for different reasons, Thomas and Anna both spoke in rational, quite detached ways about relational dilemmas. In all cases, their narratives indicated a tendency to distance themselves from feelings and relationships, which would be consistent with a more avoidant attachment style. One participant, Emma, also expressed a sense of isolation in her family of origin-"not a kind of talking family"-but evidenced a more anxious attachment style, which in her case manifested in an apparently greater need for external approval (Wei et al. 2005).

In-depth research is certainly needed fully exploring the attachment styles of humanitarian workers. In terms of the present study, however, it is simply worth noting that participants alluded to relational templates formed prior to entering the sector. It could be argued that greater awareness of these patterns, developed through either formal assessment or reflective practice, could equip humanitarians to understand potential blocks to more fulfilling relationships and thus more effectively meet their relational needs while in the field. It was certainly the case in my own experience that the stimulation and intensity of life in the field seemed for a while to compensate for a 
deep sense of internal alienation. In subsequent personal therapy, I was able to trace this back to formative emotional challenges early in life. The decision to seek therapy, however, was prompted by the realisation that while field life seemed to offer a way out of these attachment struggles, it seemed ultimately to avoid and entrench them.

\section{The search for containment}

Although psychological defences such as those described above are deployed by individuals in an attempt to maintain a sense of personal equilibrium, participants in the present study felt that they had nevertheless paid a high emotional price for working in the sector. Emma, who characterised the job as asking "for everything", described an increasing awareness over time of the impact. "By the fifth or sixth (deployment), you know ... you are knackered. Your ability to recharge and start again becomes slow. I mean I kind of had a real sense of feeling lost." The eventual impact of this, she said, was to leave her with the feeling of being "a complete failure", which prompted the decision to seek counselling and spend some time outside of the field. In line with Steiner's theory that psychic defences can work together as a refuge from the real world, Sara put it this way: "What I worry about is the longer I stay in this sector, ... you get disconnected from reality". For Julian, "it's just too much change, too much is new, too much is different ... And it costs so much energy to take it in and try to make sense of it for yourself, that you really have no time to go and share that at any meaningful level." And while Anna seemed basically content with her handling of the work, she also stated quite directly that she thought she would eventually have to leave the sector if she really wanted to have a full family life of her own.

While the majority of participants (5/6) expressed a sense of resignation in not being able to find solutions to these anxieties, their narratives did in fact yield important insights into what might help. Jane had recently returned from a residential course where relationships in and out of the field had been one of the main topics of discussion, even though the formal agenda did not include this issue. For her, the "opportunity to talk about these things, and let off steam", discovered quite by accident, seems to have been nothing short of revolutionary. She described a simple experience of naming relational difficulties in a protected space where she could show vulnerability without fear of professional consequences.

"But that might be all we need, just to go,

'That's normal, this is aid work. What do you expect?

This is a thing. You're not mad."

Given the relief this provided, she expressed a wish that her organisation could "provide people the safe spaces" to name, normalise and validate these struggles.
The two participants who had sought counselling also evidenced er an understanding of the importance of space to think through difficult challenges. Emma said that she had begun to find that friends were asking for her advice about contacting a therapist, which she saw as evidence of slowly reducing stigma around seeking that kind of support. In the organisational setting, she also echoed Jane in advocating for a "structured conversation" about relational challenges in the work, a "forum where we could talk about that with each other".

Sara felt that the current allowance in her organisation of six sessions of counselling was not enough and needed to be something "that we can tap into on a regular basis". She and two other participants also said that people were unsure about using the available Employee Assistance Programme (EAP), an out-sourced service offering a telephone helpline and a limited number of counselling sessions. Sara felt that more sustained "engagement over a longer term" was needed with "someone you can trust", a wish consistent with the attachment concept of a safe haven (Feeney and Woodhouse 2016) or the familiar and consistent presence of an available caregiver.

In terms of other suggestions, Julian felt that more preparation and guidance were needed at the beginning of the humanitarian career and Emma argued that more creative thinking was required around how workers might be able to share jobs or alternate assignments to give them enough time to create and sustain a secure base somewhere.

In different ways, participants were almost unanimously describing a wish for structured spaces offering containment of their anxieties, where difficult and potentially contradictory thoughts and feelings about their relational worlds could be named and addressed. They did not specify whether they felt this would make them more resilient or productive, although it is well established that impoverished social support is contributory factor to burnout among humanitarian workers (Brooks et al. 2015). This would support the idea that anything that might help strengthen the relationships of humanitarian workers would implicitly raise levels of resilience. On an organisational level, workplace teams where people are allowed to express vulnerability and transparency without fear of reprisal have been demonstrated to become places of psychological safety (Edmondson 1999). Once this sense of safety has been established, it then becomes a catalyst for new learning, creativity, adaptability and high performance in team environments (Agarwal and Farndale 2017). As stated previously, uncontained anxieties on an individual level have also been shown to set up a range of unproductive and defensive group behaviours in workplace settings, such as factionalization, meaningless busy-ness, avoidance of responsibility and a rigid focus on procedures at the expense of creative goals (Obholzer and Zagier Roberts 1994). Active containment of those anxieties then 
facilitates a capacity on both individual and group levels to engage in coherent thinking and creative problem solving (Obholzer and Zagier Roberts 1994; Steiner 1993). In short, the reality of life and work can be faced and addressed, rather than evaded and denied.

As noted above, further research would be needed to firmly identify causal links between the relational challenges experienced by humanitarians and their levels of personal resilience and professional productivity. The majority of participants in the present study, however, were unanimous in naming relational anxieties as a central preoccupation in their working lives. They also widely referenced the high emotional cost of these anxieties and expressed the belief that these struggles, while ubiquitous in the sector, were not adequately understood or discussed (a reason that several participants gave for agreeing to participate in the study). It could then tentatively be concluded that a deeper understanding and processing of these anxieties-including their more unconscious manifestations-would bolster a sense of personal self-awareness and efficacy and, by extension, strengthen levels of professional engagement.

\section{Conclusion and recommendations}

The present study has sought to address a broadly overlooked aspect of the humanitarian sector, namely the internal, subjective relational worlds of those who work in it. The key finding of this study indicates a core area of relational challenge within this population is the division of life into apparently incompatible parts, on both an

Table 2 Practical recommendations

Arising from the narratives, the following practical recommendations for the sector are offered:

1. Structured training and psycho-education during induction of expatriate aid workers on the relational challenges of international humanitarian work, including opportunities for workers to assess areas of potential vulnerability and explore creative coping strategies.

2. Annual psychological assessments designed to review levels of resilience and coping, with a particular focus on the maintenance of relational resources.

3. Assessment with senior management of deployment rosters to allow workers enough time out of the field to build and maintain secure relational support structures.

4. Regular facilitated workshops/retreats both at headquarters and in the field, where workers can reflect in a secure and protected space on the impact of the work, share relational dilemmas, explore possible ways forward, and create robust peer support networks.

5. Funding permitted, access to longer-term counselling support that allows individuals to maintain contact with the same therapist over time in order to promote a sense of relational reliability and continuity.

6. A follow-up project is recommended to monitor and evaluate the impact of this kind of enhanced support on levels of engagement, productivity and staff retention. Inviting a larger sample of aid workers to complete attachment style questionnaires as part of the study could also provide a much clearer picture of relational needs, which could then be used to tailor training programmes. external geographic level and an internal psychological one. The so-called double bind (Gibney 2006) of this challenge leaves individuals unable to reflect creatively, or mentalize (Fonagy et al. 2016), about possible solutions. This then drives them into erecting unconscious psychic defences against the anxiety that they feel, including splitting, projective identification (Klein 1946) and an addiction to emergency (Gleiser 2003; Van der Kolk 1989). Although unsure about how to resolve these anxieties, participants seemed to have benefited from finding protected and facilitated spaces-whether among peers or in counselling-were their struggles and legitimate needs could be named, acknowledged and processed in a way that leaves them feeling heard and understood. The myriad challenges outlined by participants in this study undoubtedly chimed with my own experiences of life in the field and reflect on many levels the stories I hear regularly in my clinical practice. I have been fortunate to find the spaces over the years where I have been able to identify and process these conflicts and dilemmas, which has led me to a place of greater integration, satisfaction and wellbeing in my life and relationships. It is my hope that this research will help other humanitarians do the same (Table 2).

\section{Endnotes}

${ }^{1}$ For the purposes of the present study, the terms "psychodynamic" and "psychoanalytic" are used interchangeably.

\section{Abbreviations}

BMJ: British Medical Journal; BRCS: British Red Cross Society; CDC: Centers for Disease Control; EAP: Employee Assistance Programme; ICRC: International Committee of the Red Cross; INGO: International Non-Governmental Organisation; ODI: Overseas Development Institute; UN: United Nations

\section{Acknowledgements \\ I would like to thank Dr. Nikki Kiyimba and Dr. Christina Buxton of the Department of Social and Political Science at the University of Chester for their consistent, engaged and responsive supervision during the research and writing of this study. I would also like to thank the human resources adviser who helped me recruit the participants for this research. This project could not have got off the ground without her facilitation and support. Sincere thanks, of course, go to the participants, who gave of their time to speak openly and honestly about highly personal issues in their lives. I would also like to thank Graham Fawcett of Thrive Worldwide for reading through the final draft. I am gratefully indebted to him for his valuable comments.}

\section{Funding}

This study was self-funded by the author.

\section{Availability of data and materials}

Due to ethical considerations arising from the personal and highly sensitive nature of the data, the datasets supporting the conclusions of this article are not publicly available. Please contact author for data requests.

\section{Author's contributions}

The author read and approved the final manuscript.

\section{Author's information}

Mark Snelling is a counsellor, psychotherapist and psychosocial consultant working in private practice in London. He specialises in supporting humanitarian 
aid workers but also works with a wide range of professional groups who operate in trauma-exposed settings. Prior to setting up his practice, he was a senior clinician with InterHealth Worldwide, an international health charity providing medical and psychological support to aid agencies, mission organisations and government departments. He has also worked in the NHS. Before training as a therapist, he was an international delegate of the British Red Cross Society, completing a number of short- and long-term assignments in areas of armed conflict and natural disaster in Africa, Asia-Pacific and the Middle East.

\section{Competing interests}

The author declares that he has no competing interests.

\section{Publisher's Note}

Springer Nature remains neutral with regard to jurisdictional claims in published maps and institutional affiliations.

\section{Received: 3 April 2018 Accepted: 2 August 2018}

\section{Published online: 12 November 2018}

\section{References}

Agarwal P, Farndale E (2017) High-performance work systems and creativity implementation: the role of psychological capital and psychological safety. Hum Resour Manag J 27:440-458. https://doi.org/10.1111/1748-8583.12148

Ager A, Pasha E, \& Yu G (2012). Stress, mental health, and burnout in national humanitarian aid workers in Gulu, northern uganda. Journal of Traumatic Stress, 25. https://doi.org/10.1002/jts.21764.

Agishtein P, Brumbaugh C (2013) Cultural variation in adult attachment: the impact of ethnicity, collectivism, and country of origin. J Soc Evol Cult Psychol 7:384-405. https://doi.org/10.1037/h0099181

Ainsworth MDS, Blehar MC, Waters E, Wall S (1978) Patterns of attachment: a psychological study of the strange situation. Erlbaum, Hillsdale

Alayarian A (2011) Trauma, torture and dissociation: a psychoanalytic view. Karnac Books, London

Allen J (2013) Mentalizing in the development and treatment of attachment trauma. Karnac Books, London

Antares Foundation (2012) Managing stress in humanitarian workers: guidelines for good practice, 3rd edn

Bateman A, Fonagy P (2012) Handbook of mentalizing in mental health practice. American Psychiatric Publishing, Arlington

Bateson G, Jackson DD, Haley J, Weakland J (1963) Toward a theory of schizophrenia. In: Smelser NJ, Smelser WT (eds) Personality and social systems. Wiley, Hoboken, pp 172-187. https://doi.org/10.1037/11302-016

Berk JH (1998) Trauma and resilience during war: a look at the children and humanitarian aid workers of Bosnia. Psychoanal Rev 85:639

Berzoff J, Kita E (2010) Compassion fatigue and countertransference: two different concepts. Clin Soc Work J 38:341-349. https:/doi.org/10.1007/s10615-010-0271-8

Bifulco A, Thomas G (2013) Understanding adult attachment in family relationships: research, assessment and intervention, vol Book, Whole. Routledge, London

Bion W (1959) Attacks on linking. Int J Psychoanal 40:308-315

Bion W (1962) A theory of thinking. Int J Psychoanal 33:306-310

Bjerneld M, Lindmark G, McSpadden LA, Garrett MJ (2006) Motivations, concerns, and expectations of Scandinavian health professionals volunteering for humanitarian assignments. Disaster Manag Response 4:49-58 https://doi.org/ 10.1016/j.dmr.2006.01.002

Blanchetiere $P$ (2006) Resilience of humanitarian workers

Bowlby J (1988) A secure base, vol Book, Whole, New edn. Abingdon: Routledge Ltd

Breuer J, Freud S (1955) Studies on Hysteria. In: Strachey J (ed) Standard edition, vol 2. Hogarth Press, London (Original work published 1895)

Brooks SK, Dunn R, Sage CAM, Amlôt R, Greenberg N, Rubin GJ (2015) Risk and resilience factors affecting the psychological wellbeing of individuals deployed in humanitarian relief roles after a disaster. J Ment Health 24:385413. https://doi.org/10.3109/09638237.2015.1057334

Cain K, Postlewait H, Thompson A (2005) Emergency sex (and other desperate measures): true stories from a war zone. Ebury Press, London

Cardozo BL et al (2012) Psychological distress, depression, anxiety, and burnout among international humanitarian aid workers: a longitudinal study. Public Libr Sci 7. https://doi.org/10.1371/journal.pone.0044948

Casement P (2014) On learning from the patient, vol Book, Whole, Classic edn. Routledge, Hove; New York
Connorton E, Perry MJ, Hemenway D, Miller M (2012) Humanitarian relief workers and trauma-related mental illness. Epidemiol Rev 34:145

Croucher S (2012) Privileged Mobility in an Age of Globality. Societies 2:1-13. https://doi.org/10.3390/soc2010001.

Cyrulnik B (2009) Resilience: how your inner strength can set you free from the past. Penguin Books, London

Danieli Y (1996) Who takes care of the caretakers? The emotional life of those working with children in situations of violence. In: Appel RJ, Simon B (eds) Minefields in their hearts: the mental health of children in war and communal violence. Yale University Press, New Haven, pp 189-205

Davey E, Borton J, Foley M (2013) A history of the humanitarian system: western origins and foundations. HPG Working Paper

de Haan BB (1998) Emotional group debriefing of humanitarian aid workers: the experience of ICRC

de Haan BB (2001) Humanitarian action and armed conflict: coping with stress

de Waal A (1997) Famine crimes: politics and the disaster relief industry in Africa. Indiana University Press, Bloomington

Deci EL, Vansteenkiste M (2004) Self-determination theory and basic need satisfaction: understanding human development in positive psychology. Ricerche di Psicologia 27:23-40

Dodds P (2017) UN peacekeepers in Haiti implicated in child sex ring

Duffield M (1994) Complex emergencies and the crisis of developmentalism Institute of Development Studies Bulletin 25

Dunkley F (2018) Psychosocial support for humanitarian aid workers: a roadmap of trauma and critical incident care. Routledge, Abingdon

Easterley W (2007) The white man's burden: why the West's efforts to aid the rest have done so much ill and so little good. Oxford University Press, Oxford

Edmondson A (1999) Psychological safety and learning behavior in work teams. Adm Sci Q 44:350-383. https://doi.org/10.2307/2666999

Ehrenreich J (1999). The Humanitarian Companion: A guide for international aid, development and human rights workers. ITDG Publishing, Bradford.

Ehrenreich JH, Elliott TL (2004) Managing stress in humanitarian aid workers: a survey of humanitarian aid agencies' psychosocial training and support of staff. Peace Confl: J Peace Psychol 10:53-66. https://doi.org/10.1207/ s15327949pac1001_4

Erdman P, Ng K-M (2010) Attachment: expanding the cultural connections, vol Book, Whole. Routledge, London

Eriksson CB, Kemp HV, Gorsuch R, Hoke S, Foy DW (2001) Trauma exposure and PTSD symptoms in international relief and development personnel. J Trauma Stress 14:205-212. https://doi.org/10.1023/A:1007804119319

Eriksson CB et al (2009) Social support, organisational support, and religious support in relation to burnout in expatriate humanitarian aid workers mental health. Relig Cult 12:671-686. https://doi.org/10.1080/13674670903029146

Eriksson CB et al (2013) Predeployment mental health and trauma exposure of expatriate humanitarian aid workers: risk and resilience factors. Traumatology 19:41-48. https://doi.org/10.1177/1534765612441978

Etherington K (2004) Becoming a reflexive researcher: using ourselves in research, vol Book, Whole. Jessica Kingsley, London; Philadelphia

Fawcett J (2003) Stress and trauma handbook: strategies for flourishing in demanding environments. World Vision International, Monrovia

Fechter A-M (2007) Transnational lives: expatriates in Indonesia. Routledge, Abingdon

Fechter A-M (2012a) 'Living well' while 'doing good'? (missing) debates on altruism and professionalism in aid work. Third World Q 33:1475-1491. https://doi.org/10.1080/09700161.2012.698133

Fechter A-M (2012b) The personal and the professional: aid workers' relationships and values in the development process. Third World Q 33:1387-1404. https://doi.org/10.1080/01436597.2012.698104

Feeney BC, Woodhouse SS (2016) Caregiving. In: Cassidy J, Shaver P (eds) Handbook of attachment: theory, research, and clinical applications, 3rd edn. The Guildford Press, New York

Fonagy P et al (2016) Development and validation of a self-report measure of mentalizing: the reflective functioning questionnaire. PLoS One 11. https:// doi.org/10.1371/journal.pone.0158678

Freud A (1968a) The ego and the mechanisms of defence. The International Psycho-Analytical Libray Hogarth Press/Institute of Psychoanalysis, London

Freud S (1940) Splitting of the ego in the process of defence. In: Strachey J (ed) Standard edition, vol 23. Hogarth Press, London, pp 271-278

Freud S (1957a) Beyond the pleasure principle. In: Strachey J (ed) Standard edition, vol 18. Hogarth Press, London (Original work published 1920)

Freud S (1957b) Mourning and melancholia. In: Strachey J (ed) Standard edition, vol 14. Hogarth Press, London, pp 243-258 (Original work published 1917) 
Freud S (1957c) On narcissism: an introduction. In: Strachey J (ed) Standard edition vol 14. Hogarth Press, London, pp 73-102 (Original work published 1914)

Freud S (1968b) Repression. In: Strachey J (ed) Standard edition, vol 14. Hogarth Press, London, pp 141-158 (Original work published 1915b)

Frosh S, Emerson PD (2005) Interpretation and over-interpretation: disputing the meaning of texts. Qual Res 5:307-324. https://doi.org/10.1177/ 1468794105054457

Frosh S, Saville Young L (2008) Psychoanalytic approaches to qualitative psychology. In: Willig C, Stainton-Rogers W (eds) Qualitative research in psychology. SAGE Publications, London

Gibney P (2006) The double bind theory: still crazy-making after all these years. Psychother Australia 12:48-55

Gleiser KA (2003) Psychoanalytic perspectives on traumatic repetition. J Trauma Dissociation 4:27-47. https://doi.org/10.1300/J229v04n02_03

Goldman W (2012) Adventures in the screen trade. Grand Central Publishing, New York

Hawkins P, Shohet R (2012) Supervision in the helping professions, vol Book, Whole, 4th edn. Open University Press, Maidenhead

Heimann P (1950) On Countertransference. International Journal of Psychoanalysis. 31:81-84.

Hinshelwood RD (1991) A dictionary of Kleinian thought, 2nd edn. Free Association, London

Hollway W, Jefferson T (2013) Doing qualitative research differently: a psychosocial approach, vol Book, Whole, 2nd edn. SAGE Publications, London

Holmes J (2001) The search for the secure base: attachment theory and psychotherapy, vol Book, Whole. Brunner/Routledge, London; Philadelphia

Holmes J (2013) Using psychoanalysis in qualitative research: countertransference-informed researcher reflexivity and defence mechanisms in two interviews about migration. Qual Res Psychol 10:160-173. https://doi. org/10.1080/14780887.2011.586451

Holmes J (2014) John Bowlby and attachment theory, vol Book, Whole, 2nd edn. Routledge, Taylor \& Francis Group, New York; London

Horney K (1972) Our inner conflicts: a constructive theory of neurosis. W. W. Norton \& Company, New York

Inter-Agency Regional Analysts Network (2017) The future of aid: INGOs in 2030

Joseph B (1985) Transference: the total situation. Int J Psychoanal 66:447-454

Karray A, Coq J-M, Bouteyre E (2017) Delivering online clinical interviews with NGO workers in humanitarian and cross-cultural contexts. Int Perspect Psychol 6:115-131. https://doi.org/10.1037/ipp0000069

Kim HS, Sherman DK (2007) 'Express yourself': culture and the effect of selfexpression on choice. J Pers Soc Psychol 92:1-11. https://doi.org/10.1037/ 0022-3514.92.1.1

Klein M (1946) Notes on some schizoid mechanisms. Int J Psychoanal 27:99-110

Lemma A, Target M, Fonagy P (2011) Brief dynamic interpersonal therapy: a clinician's guide. Oxford University Press, Oxford

Macnair R (1995) Room for Improvement. Overseas Development Institute,

McCall M, Salama P (1999) Selection, training, and support of relief workers: an occupational health issue. BMJ 318:113-116. https://doi.org/10.1136/bmj.318. 7176.113

McCormack L, Joseph S (2013) Psychological growth in humanitarian aid personnel: reintegrating with family and community following exposure to war and genocide. Community Work Fam 16:147-163. https://doi.org/10. $1080 / 13668803.2012 .735478$

McDougall J (1982) Theatres of the mind: illusion and truth on the psychoanalytic stage. Free Association Books, London

McKay L (2007) On the road again: coping with travel and re-entry stress. Headington institute. http://headington-institute.org/files/travel-stress_ moduletemplate2_edited_82539.pdf. Accessed 16 Jan 2018

Mesman J, van ljzendoorn M, Sagi-Schwartz A (2016) Cross-cultural patterns of attachment: universal and contextual dimensions. In: Cassidy J, Shaver P (eds) Handbook of attachment: theory, resarch, and clinical applications, 3rd edn. The Guildford Press, New York/London

Mitchell S (2000) Relationality: from attachment to intersubjectivity. Routledge, London

Moyo D (2010) Dead aid: why aid is not working and how there is another way for Africa Penguin, London

Naparstek B (2005) Invisible heroes: survivors of trauma and how they heal. Bantam Books, New York

O'Neill S (2018) Top Oxfam staff paid Haiti survivors for sex

Obholzer A, Zagier Roberts V (1994) The unconscious at work: individual and organizational stress in the human services. Routledge, London
Orbinski J (2008) An imperfect offering: dispatches from the medical frontline. Text Publishing Company, Melbourne

Ozbay F, Johnson DC, Dimoulas E, Morgan CA, Charney D, Southwick S (2007) Social support and resilience to stress: from neurobiology to clinical practice. Psychiatry 4:35

Papadopoulos R (2002) Therapeutic care for refugees: no place like home. Karnac Books, London

People in Aid (2003) Code of best practice in the management and support of aid personnel, 2nd edn. London: People in Aid

Pigni A (2016) The idealist's survival kit: 75 simple ways to prevent burnout. Parallax Press, Berkely

Porter B, \& Emmens B. (2009). Approaches to staff care in international ngos. Retrieved from London: https://www.chsalliance.org/files/files/Resources/ Articles-and-Research/approaches-to-staff-care-ininternational-ngos.pdf. Accessed 5 Jan 2018.

Quevillon RP, Gray BL, Erickson SE, Gonzalez ED, Jacobs GA (2016) Helping the helpers: assisting staff and volunteer workers before, during, and after disaster relief operations. J Clin Psychol 72:1348-1363. https://doi.org/10. 1002/jclp.22336

Redfield P (2012a) Humanitarianism. In: Fassin D (ed) A companion to moral anthropology. Wiley-Blackwell, Malden, pp 451-467

Redfield P (2012b) The unbearable lightness of ex-pats: double binds of humanitarian mobility. Cult Anthropol 27:358-382. https://doi.org/10.1111/j. 1548-1360.2012.01147.x

Reich JW, Zautra A, Hall JS (2012) Handbook of adult resilience, vol Book, Whole. Guilford, New York

Riddell R (2008) Does foreign aid really work? Oxford University Press, New York

Seligman M (1990) Learned optimism: how to change your mind and your life. Vintage Books, New York

Silverman C (2005) Misfits, mercenaries and missionaries [blog post]. http:// ordinary.blogs.com/clips/aidworkers.pdf

Skeoch K, Stevens GJ, Taylor M (2017) Future role aspirations, achievement motivations and perceptions of personal help-seeking among humanitarian aid trainees. J Int Humanitarian Action 2:1-10. https://doi.org/10.1186/ s41018-017-0027-y

Slim H (1995) The continuing metamorphosis of the humanitarian practitioner: some new colours for an endangered chameleon. Disasters 19:110

Stack Sullivan H (1968) The interpersonal theory of psychiatry. W. W. Norton \& Company, New York

Steiner J (1993) Psychic retreats: pathological organizations in psychotic, neurotic and borderline patients. Routledge, Hove

Tassell N, Flett R (2007) Obsessive passion as an explanation for burnout: an alternative theoretical perspective applied to humanitarian work. Aust J Rehabil Counsel 13:101-114

Tassell N, Flett R (2011) Motivation in humanitarian health workers: a selfdetermination theory perspective. Dev Pract 21:959-973. https://doi.org/10. 1080/09614524.2011.590889

Thomas R (2016) Psychological stress: aid workers in complex humanitarian emergencies. Lambert Academic Publishing, Saarbrucken

Tummala-Narra P (2015) Cultural competence as a core emphasis of psychoanalytic psychotherapy psychoanalytic. Psychology 32:275-292. https://doi.org/10.1037/a0034041

UNHCR (2001) Managing the stress of humanitarian emergencies

Vallerand RJ et al (2003) Les passions de l'âme: on obsessive and harmonious passion. J Pers Soc Psychol 85:756-767. https://doi.org/10.1037/0022-3514.85. 4.756

Van der Kolk BA (1989) The compulsion to repeat the trauma. Re-enactment, revictimization, and masochism. Psychiatr Clin North Am 12:389

Vaux T (2001) The selfish altruist: relief work in famine and war. Earthscan, London

Volkan V (2017) Immigrants and refugees: trauma, perennial mourning, prejudice, and border psychology. Karnac Books, London

Wall S (2008) Easier said than done: writing an autoethnography. Int J Qual Methods 7:38-53. https://doi.org/10.1177/160940690800700103

Wei M, Mallinckrodt B, Larson LM, Zakalik RA (2005) Adult attachment, depressive symptoms, and validation from self versus others. J Couns Psychol 52:368377. https://doi.org/10.1037/0022-0167.52.3.368

Wilden A, Wilson T (1976) The double bind: logic, magic, and economics. In: Sluzki C, Ransom D (eds) Double bind: the foundation of communicational approach to the family. Grune and Stratton, New York, pp 263-286 